\title{
Research on Reducing Business Oral English Classroom Anxiety by Cooperative Learning

\author{
Ling-Jing SONG
}

\author{
School of Foreign Languages, Nanyang Institute of Technology, Nanyang, Henan \\ smilingalison@126.com
}

Keywords: Foreign Language Anxiety, Cooperative Learning, Business Oral English.

\begin{abstract}
This paper investigated whether cooperative learning (CL) has positive effect on reducing Foreign Language Anxiety (FLA) in business oral English classrooms and improving students' business oral English achievement. In order to find the result, the author just comprehensively applied all kinds of CL methods into her specific teaching practice. The questionnaire about FLA and oral English test were conducted before and after the experiment; besides that an interview was also made after the experiment. After the experiment, the data were analyzed. The results of the study points out that CL, if it can be applied successfully into the teaching practice, can reduce business English language anxiety efficiently and improve students' business oral English proficiency effectively.
\end{abstract}

\section{Introduction}

Foreign language anxiety and cooperative learning are gaining much attention in recent researches home and abroad. And this paper investigated whether CL can effectively reduce FLA.

With the increasing attention and research to the affective variables in foreign language learning, anxiety, as the most prominent affective factors, has been one of the main concerns of linguists in the last decade. FLA refers to the fear or apprehension occurring when a learner is expected to perform in a second or foreign language. It is a pervasive obstruction in foreign language learning, and affects all the three stages (the input stage, the processing stage, and the output stage) of cognitive processing in second language acquisition. Speaking is more vulnerable to FLA than other language activities, and most learners' low oral English proficiency just results from the FLA.

As for the negative effect of anxiety, a great many of scholars have explored a series of methods and countermeasures. CL, as one of the ways to relieve anxiety, has attracted much attention. CL is a creative and effective teaching theory and strategic system applied by many countries in the world now, and is regarded as the most important and successful teaching reform in the last decade. Olsen and Kagan (1992) define CL as "dependent on the socially structured exchange of information between learners in groups and in which each learner is held accountable for his or her own learning and is motivated to increase the learning of others".

Many teachers have realized the effectiveness of CL and brought it into their teaching practice. However, some of them in fact fail to grasp the essence by merely organizing students into groups to learn. Sometimes the top student may dominate in a group, and the others, especially the students who have comparatively low oral abilities just lose the chances to practice. And for some "lazy" students, it just offers them a "safe" place in a group where they can keep silent. There is a great difference between a traditional group and a cooperative group. Simply making students work in small groups does not mean that they can cooperate effectively to ensure their own learning and the learning of the others within their group (Johnson, Johnson \& Holubec, 1993). CL has to be well structured. To successfully set up groups and have student complete tasks within a CL framework, some essential requirements or elements must be met. The following five basic elements (Johnson, Johnson \& Holubec, 1993) are just essential and indispensable to ensure cooperativeness.

1) Positive Interdependence; 2) Face-to-face Promotive Interaction; 3) Individual and Group Accountability; 4) Interpersonal and Small Group Skills; 5) Group Processing

CL enjoys broad acceptance in a large number of language learning classrooms. At the same time, 
many scholars have studied and provided various methods and have offered very detailed descriptions of the CL methods which have been proven successful in some areas. And the most famous ones are: Student Teams Achievement Divisions (STAD), Group Investigation (GI), Learning Together, Role-Play and Think-Pair-Share.

Although many researches home and abroad have demonstrated that CL has positive impact on reducing anxiety and improving learning effectiveness, only a quite small amount of them is related to foreign or second language learning, and it is more rare in oral language learning. From the aspect of business oral English learning, the reduction of FLA by CL is virtually a research blank. For these business English major students, who tend to find jobs in the field of foreign trade after graduation, oral English proficiency is one of the most important skills they need to acquire, and also one of the most widely used abilities in their future career. Thus, the study focusing on reducing these students' oral English anxiety and improving their oral English proficiency is of great necessity.

Therefore this paper investigated whether CL has positive effect on reducing FLA in business oral English classrooms and improving students' business oral English achievement. The present study addressed the following questions: 1) Do English majors (who specialize in business English) in local universities suffer FLA in their business oral English classroom? 2) Does CL have positive effect on reducing learner's FLA in business oral English class? 3) Can CL effectively improve students' business oral English proficiency?

\section{Research Design}

In order to find the result, the author just comprehensively applied all kinds of CL methods into her specific teaching practice. Some CL methods maybe get modified, altered and combined so as to fit the practical needs, but the spirit of CL were insisted and reflected. The research took 60 students from 2 junior classes in English major (who specialized in business English) as subjects, and in the sixteen-week CL experiment, CL models were applied in the experimental group (EG), whereas the control group ( $\mathrm{CG}$ ) still used the traditional teaching methods.

The instruments used in this research included questionnaire, oral test, and interview. For the questionnaire, the author used authoritative FLCAS (the Foreign Language Classroom Anxiety Scale). For the oral test, the author adopted the oral test in BEC (Business English Certificate) vantage, which is reliable and professional for business English. And for the interview, the author selected several typical problems. Three kinds of data were collected: the scores of FLCAS, the scores of BEC vantage oral test and the notes of interview.

In order to assess the effects of the experiment, the questionnaire about FLA and oral English test were conducted before and after the experiment; besides that an interview was also made after the experiment. After the experiment, the data were analyzed in two different methods. First, the quantitative data obtained from the questionnaires and oral tests were analyzed by SPSS 13.0. Second, the qualitative data gained from the interview were categorized and summarized to find the answer to the research question proposed before.

\section{Data Analysis}

After the application of CL models, the data were analyzed by SPSS13.0 (Statistical Product and Service Solutions13.0) in the following, which will reveal the difference between CG and EG. 
Table 1 T-test of FLA Levels in EG before and after the Experiment

Paired Samples Statistics

\begin{tabular}{|ll|l|r|r|c|}
\hline & & & & Std. Error \\
& & Mean & N & Std. Deviation & \multicolumn{1}{c|}{ Mean } \\
\hline Pair & Pretest & 92.2333 & 30 & 18.19375 & 3.32171 \\
1 & Posttest & 80.3333 & 30 & 15.46148 & 2.82287 \\
\hline
\end{tabular}

Paired Samples Correlations

\begin{tabular}{|ll|r|r|r|}
\hline & $\mathrm{N}$ & Correlation & \multicolumn{1}{c|}{ Sig. } \\
\hline Pair 1 & Pretest \& Posttest & 30 & .987 & .000 \\
\hline
\end{tabular}

Paired Samples Test

\begin{tabular}{|c|c|c|c|c|c|c|c|c|c|}
\hline & & \multicolumn{5}{|c|}{ Paired Diff erences } & \multirow[b]{3}{*}{$\mathrm{t}$} & \multirow[b]{3}{*}{ df } & \multirow{3}{*}{$\begin{array}{l}\text { Sig. } \\
(2-t \\
\text { aile } \\
\text { d) }\end{array}$} \\
\hline & & \multirow[b]{2}{*}{ Mean } & \multirow{2}{*}{$\begin{array}{c}\text { Std. } \\
\text { Deviati } \\
\text { on } \\
\end{array}$} & \multirow{2}{*}{$\begin{array}{l}\text { Std. } \\
\text { Error } \\
\text { Mean }\end{array}$} & \multicolumn{2}{|c|}{$\begin{array}{l}95 \% \text { Confidence } \\
\text { Interv al of the } \\
\text { Diff erence }\end{array}$} & & & \\
\hline & & & & & Lower & Upper & & & \\
\hline $\begin{array}{l}\text { Pair } \\
1\end{array}$ & $\begin{array}{l}\text { Pretest - } \\
\text { Posttest }\end{array}$ & 11.90000 & 3.80879 & 69539 & 10.47777 & 13.32223 & 17.113 & 29 & .000 \\
\hline
\end{tabular}

Table 1 shows the students' FLA levels in the EG before and after the experiment. As shown in this table, the mean score of the students' FLA before the experiment was 92.2333, while after the experiment was 80.3333, with the mean difference of 11.9. Meanwhile the 2-tailed significance $(p=0.000)$ was much lower than 0.05 and 0.045 (Table 5-4), which indicates that there was greater difference in FLA level in EG than that in CG before and after the experiment. The 95\% confidence interval of the difference did not include the zero, which again testifies the significant difference. It reveals that the students in EG became much less anxious after the application of CL model.

Table 2 T-test of FLA Levels in EG and CG after the Experiment

Group Statistics

\begin{tabular}{|ll|r|r|r|c|}
\hline & Group & $\mathrm{N}$ & Mean & Std. Dev iation & $\begin{array}{c}\text { Std. Error } \\
\text { Mean }\end{array}$ \\
\hline Posttest & EG & 30 & 80.3333 & 15.46148 & 2.82287 \\
& CG & 30 & 93.0333 & 17.06475 & 3.11558 \\
\hline
\end{tabular}

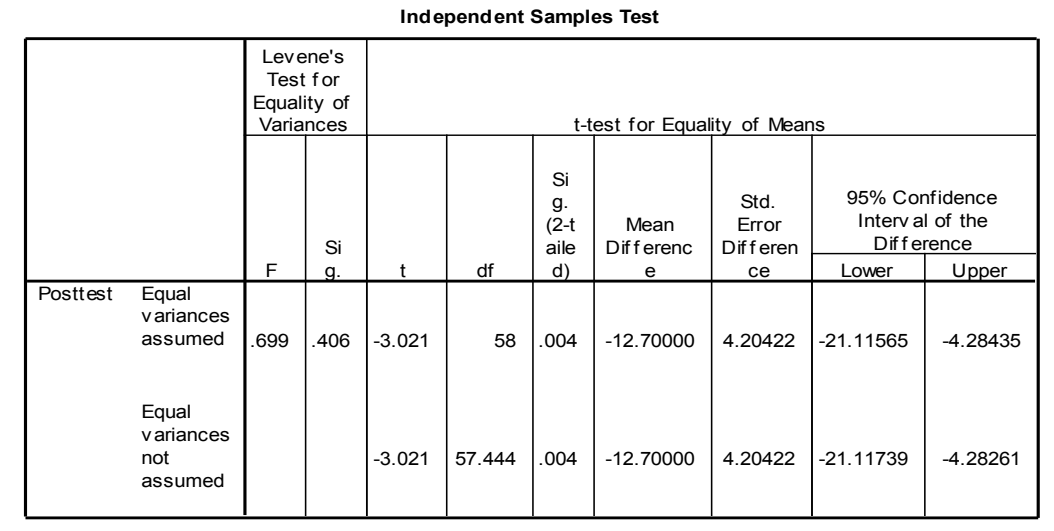

Table 2 shows the students' FLA levels both in EG and CG after the experiment. As illustrated in this table, the mean score of the students' FLA in EG was 80.3333, while in CG was 93.0333, which was much higher than that of EG. Also the 2-tailed significance $(p=0.004)$ was much lower than 
0.05, which indicates that there was significant difference in FLA level between the two groups after the experiment. And the 95\%confidence interval of the difference did not include the zero, which testifies the significant difference once again.

Table 3 T-test of Oral Test Scores between EG and CG before the Experiment

Group Statistics

\begin{tabular}{|cl|r|r|r|c|}
\hline & Group & $\mathrm{N}$ & Mean & Std. Dev iation & $\begin{array}{c}\text { Std. Error } \\
\text { Mean }\end{array}$ \\
\hline pretest & EG & 30 & 77.4333 & 9.01984 & 1.64679 \\
& CG & 30 & 77.1000 & 7.29360 & 1.33162 \\
\hline
\end{tabular}

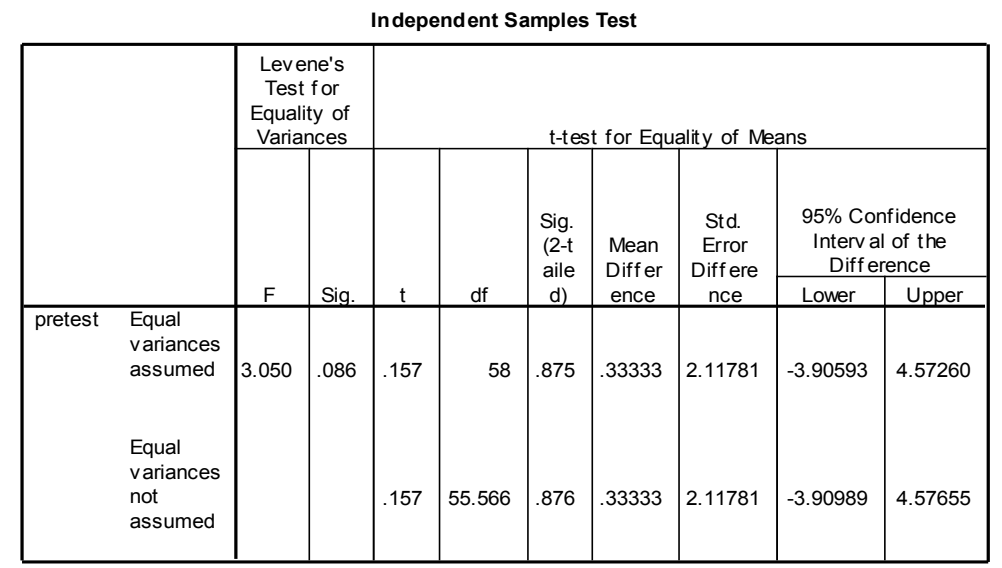

As shown in table 3, the mean score of students' business oral test in CG (77.1000) before the experiment was slightly lower than that in EG (77.4333), and the standard deviation of CG (7.29360) was also lower than that of the EG (9.01984). Nevertheless, the 2-tailed significance ( $\mathrm{p}=0.875$ ) was much higher than 0.05 , which demonstrates that although there were slight differences between the two groups before the experiment, the differences were not statistically significant. The $95 \%$ confidence interval of the difference included the zero value, which confirms it once again. All of these prove that the two groups could be taken as equivalents in oral English proficiency before the experiment .Comparison of Oral Test Scores between EG and CG after the Experiment

Table 4 T-test of Oral Test Scores between EG and CG after the Experiment

\section{Group Statistics}

\begin{tabular}{|ll|r|r|r|c|}
\hline & Group & $\mathrm{N}$ & Mean & Std. Deviation & $\begin{array}{c}\text { Std. Error } \\
\text { Mean }\end{array}$ \\
\hline posttest & EG & 30 & 84.0333 & 7.10747 & 1.29764 \\
& CG & 30 & 79.1667 & 7.29706 & 1.33226 \\
\hline
\end{tabular}

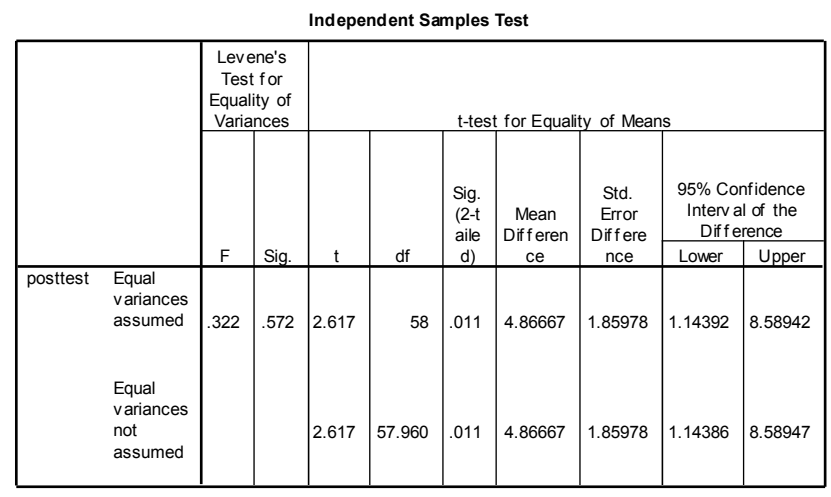


As shown in table 4, the mean score of students' business oral test in CG (79.1667) after the experiment was much lower than that in EG (84.0333). The mean difference was 4.86667. Meanwhile, the 2-tailed significance $(\mathrm{p}=0.011)$ was much lower than 0.05 , which demonstrates that there were significant differences in business oral English proficiency between the two groups after the experiment. The $95 \%$ confidence interval of the difference did not include the zero, which confirms the significant differences once again.

On the basis of the tables and analyses above, it is easy to get the conclusion that compared with the traditional teaching methods, CL is more efficient and effective on improving students' business oral English proficiency.

\section{Conclusion}

The results of the study points out that a large proportion of English majors specializing in business English in local universities suffer FLA in their business oral English classroom, and their classroom anxiety is a big obstacle to the improvement of their business oral English ability. CL, if it can be applied successfully into the teaching practice, can reduce business English language anxiety efficiently and improve students' business oral English proficiency effectively.

As we know, the different aspects of affective factors, including motivation, self-esteem, self-confidence, positive attitude and anxiety, are mutually influenced. This means that learners' enhanced motivation, self-esteem and positive attitudes also facilitate reducing anxiety. And CL has been shown to encourage and support most of the affective factors which correlate positively with language learning: improving self-confidence and self-esteem, increasing motivation, and promoting positive attitudes. Besides that, CL can facilitate creating a harmonious classroom climate, and increase language practice opportunities, which will in the end have positive effect on the reduction of anxiety. In fact, just because CL has these advantages and features, it can help to reduce FLA effectively.

Although CL is effective in reducing students' anxiety, it is not definitely efficient to reduce every student's anxiety. From the findings of the interview after the experiment, it is found that some students just cannot accept CL, as they disliked communicating with others, and they preferred the traditional teaching methods. Therefore, during the application of CL, we still need to pay attention to the individual difference, and find some ways to deal with the specific situation.

In order to relieve anxiety in oral English class, the author suggests the following recommendations:

1) Raise teachers and students' awareness of FLA and its negative effect on foreign language learning, and find possible measures to reduce it. This can be achieved by presentations elaborating FLA or discussions on the possible ways of anxiety reduction. It is also crucial for teachers to get familiar with the FLCAS instrument (Horwitz et al., 1986) so as to better understand the sources of students' anxiety. Teachers should try their best to create a friendly, harmonious, cooperative and supportive learning environment in the classroom, establish good relationships with students, and involve students regularly in discussions on their feelings concerning English learning. Since the reasons that lead to FLA are very complicated, it is of great importance for teachers to make it clear what exactly causes his or her own students' language anxiety. Then teachers can adapt the relative methods and adjust their teaching approaches based on the students' needs.

2) During the application of CL, teachers must grasp the essence of CL and combined CL methods with practical situations. In other words, teachers should not mechanically apply the CL methods; they should consider the characteristics of their lesson, the students' intelligence and language aptitude, students' likes and dislikes, the teaching objectives and so on. Some changes can be made when necessary so as to make these methods more suitable for the practical situations as long as observing the basic principle of CL. Moreover, teachers should try to complete the relevant evaluation system to ensure the group work's significance. And the monitoring system should also be established so as to ensure the real CL spirit is kept all the time.

3) Be objective to CL. CL is not omnipotent and it also has its limitations. It just has limited 
effectiveness in reducing test anxiety (one of the four types of FLA). And it is not definitely efficient to reduce every student's anxiety. Therefore, during the application, teachers must realize the defects of CL, pay more attention to individual difference, and use other ways such as some psychological methods to relieve students' test anxiety and help them to develop excellent psychological quality.

4) Pay attention to other affective factors, such as motivation, self-esteem, self-confidence, positive attitude, let them reinforce each other mutually and form a virtuous circle of promotion.

\section{References}

[1] Johnson, D. W., Johnson, R. T. \& Holuhec E. J. Circles of Learning: Cooperation in the Classroom [M]. Edina, MN: International Book Company, 1993.

[2] Horwitz. E. K. Preliminary evidence for the reliability and validity of a foreign language anxiety scale [J]. TESOL Quarterly, 1986(20): 559-562.

[3] Olsen, R. \& Kagan, S. About Cooperative Learning [A]. In C. Kessler, (Ed), Cooperative Language Learning: A teacher's Resource Book [C]. Englewood Cliffs. NJ: Prentice Hall Regents, 1992: 1-30. 